\title{
Evaluation of the Effect of Farmer Input Support Program (FISP) on Small-Scale Farmers in the Kara Region of Togo
}

\author{
John-Philippe Essiagnon Alavo ${ }^{1,2}$, Emefa Adzowa-Sika Cogbe ${ }^{1,2}$, Xiangmei $\mathrm{Li}^{1,2,3}$, \\ Gershom Mwalupaso Endelani ${ }^{1}$, Ekram Abdalgadir Eltom ${ }^{1}$, Mariko Korotoumou ${ }^{1} \&$ Aseres Mamo Ethetie ${ }^{1}$ \\ ${ }^{1}$ College of Economics and Management, Nanjing Agricultural University, Nanjing, China \\ ${ }^{2}$ China Center for Food Security Studies, Nanjing Agricultural University, Nanjing, China \\ ${ }^{3}$ Department of Earth Sciences, Montana State University, Bozeman, MT, USA \\ Correspondence: Xiangmei Li, College of Economics and Management, Nanjing Agricultural University, No. 1 \\ Weigang, Nanjing 210095, China; Department of Earth Sciences, Montana State University, Bozeman, MT, \\ USA. Tel: 86-135-8510-3984.E-mail: xmeili@njau.edu.cn; xiangmei.li@montana.edu
}

$\begin{aligned} & \text { Received: December 19, } 2018 \quad \text { Accepted: January 29, } 2019 \\ & \text { doi:10.5539/jas.v11n4p35 }\end{aligned}$ URL: https://doi.org/10.5539/jas.v11n4p35

The research is financed by the National Natural Science Foundation of China [71573127] and the Natural Science Foundation of Jiangsu Province of China [BK20171384].

\begin{abstract}
The government of Togo reintroduced Farmer Input Support Program (FISP) as one of its Poverty Reduction Strategies (PRS) in 2002. Since the introduction of the program, the studies that evaluate its effects on income have focused either on fertilizer or seed component, but not on both, which made it a challenge to find out what improvements in small-scale farmers' productivity can be attributed to FISP as a whole. Using Propensity Score Matching technique with collected data from 150 randomly surveyed households in the Kara region of Togo, the authors of the study estimated the impact of FISP on beneficiary households' output from maize production. The results show that FISP augmented household annual maize income by $30.8 \%$ and total household income by $13.9 \%$ for both 2016/17 and 2017/18 cropping seasons. However, even though FISP is achieving its objective of improving small-scale farmers' income, this increment is still not large enough to take households above the poverty line, and the effects of FISP to reduce overall poverty is also limited.
\end{abstract}

Keywords: Farmer Input Support Program (FISP), agricultural productivity, Poverty Reduction Strategies (PRS), propensity score matching technique, the Kara region of Togo

\section{Introduction}

Fighting rural poverty in Low-Income Countries (LICs) whose economic sectors facilitate dualism regarding economic growth and development remains a serious challenge to their governments. Compounding the problem is when such a country is in sub-Sahara Africa, where low asset possession accompanies poverty (Oya, 2009). Even more difficult is the choice of policy to tackle this problem. As a compelling sector, agricultural policy is one obvious candidate for most LICs (Rosenzweig \& Wolpin, 1993). This choice comes with many challenges because the evaluation of such policies becomes difficult at the local farmer level. However, with well-structured asset-based methods (UNICEF, 2000), inroads are being made on estimating how effective these aggressive agro-based policies could be. This research paper tries to assess the effectiveness of the Farmer Input Support Program (FISP) in fighting rural poverty for sustainable agriculture in Togo.

Agricultural input subsidy programs in Togo have existed since independence in the 1960s. The programs mainly focused on subsidizing fertilizer (Mougeot, 2005) and only over the past two decades was hybrid maize seed included in the programs. In Togo, one of the most important food crops is maize, and farmers have promoted its cultivation in all parts of the country (without due consideration to agronomic suitability) since the 1960's independence era. It is predominant in both production and consumption. Maize is the primary staple crop of Togo, and over 90 percent of smallholder farmers rely on it for food security and income generation (Pretty, 1999). 
Maize and input subsidies, to support its production, have been central to the social contract between the government of Togo (Binswanger, 1989) and the Togolese people (Crawford et al., 2006). Under the social contract of the 1980s, the massive government expenditures were fiscally unsustainable, and, as such, market reforms under the Structural Adjustment Program (SAP) were introduced in the early 1990s. Among other changes under SAP, direct input subsidies were eliminated, and private traders and distributors were allowed to enter the agricultural sector. Due to the limited purchasing power of small-scale farmers and lack of good roads to reach remote areas, the private sector had little incentive to supply the created markets effectively, and as such, various programs were launched to improve the situation. These included the Agricultural Input Revolving Funds, Fertilizer Loan Supplier Fund, and the Trader/Agency Training Facility. In 1994, the government abandoned these efforts because the credit recovery was weak, and the Agricultural Credit Management Program (ACMP) was launched. ACMP also suffered from meager credit recovery (the recovery was only about 5-10\% of the total disbursements) and was subsequently terminated in 1997, leaving the Food Reserve Agency (FRA) to function as input distributor (Wendland \& Sills, 2008).

In the early 2000s, the New Deal Government noted that the lack of cash incomes, appropriate technological packages, and irregular supply of investment were the constraints that affected the activities of small-scale farmers, who constituted about $80 \%$ of farm households in the country. It is recognized that a large proportion of small-scale farmers in rural areas depends on agriculture for sustenance. However, they were too weak economically to provide adequate demand for fertilizer. Therefore, in 2002 the Fertilizer Support Program (FSP) was established under the Poverty Reduction Strategy Paper (PRSP) as one of the five programs created to increase food production and enhance food security among small-scale farmers. It supplied fertilizer and seeds at a 50\% subsidy (Vlek, 1990). The overall goals of FSP were: "improving household and national food security, incomes, and accessibility to agricultural inputs by small-scale farmers and building the capacity of the private sector to participate in the supply of agricultural inputs" (Tittonell \& Giller, 2013). The FSP employed a cash system whereby the expected beneficiaries, through their cooperatives, made down payments depending on the level of subsidy for fertilizer and maize seed for every hectare cultivated land. Based on FSP, each small-scale farmers would own one hectare of cultivated land, and also would be subsided 200kg fertilizer (there are four bags basal fertilizer and one bag urea fertilizer).

In 2005, in ordered to expand the scope of small-scale farmers who got the subsidies, President Faure E. Gnassingbe renamed FSP to Farmer Input Support Program (FISP), reduced the subsidy of fertilizer and maize seeds to half which was $100 \mathrm{~kg}$ fertilizer and $10 \mathrm{~kg}$ of hybrid maize seed for each small-scale family. Subsequently, this policy led to the fragmentation of cultivated land, because the eligibility based on area cultivated under maize was reduced from 1 ha to 0.5 ha. The FISP doubled the number of beneficiaries with the same of subsidy, attracted local leaders in the selection of beneficiaries, and also expanded the range of crops included in the program (rice in 2010/11 season, and cotton, soybeans, sorghum, and groundnuts in 2012/13 season).

The new subsided policy stimulated the productivity of maize in Togo, the World Bank (2010) estimated a total increment in maize production of 96,000 tons in 2007/8 season, while $69 \%$ growth caused by the FISP. However, the growth of maize productivity did not reduce poverty effectively; every four out of five people who live in the rural area are still live on less than the US $\$ 2$ per day. Despite the continued support through subsidizing agricultural investment mainly for maize production to small-scale farmers, the program has not helped to improve small-scale farmers' maize production and household income. Therefore, this research seeks to measure the impact of FISP on rural household income, and subsequently its poverty reduction implication.

\section{Materials and Methods}

\subsection{Study Area}

This study was conducted in the Bassar Prefecture in the Kara region of Togo. Kara is located between Central Region and Savanes Region. Its capital city is Kara, with a population of about 100,000 inhabitants; it is a significant marketplace in Northern Togo with appropriate infrastructure. Niamtougou International Airport, more likely a regional airport, is located near the city. Some traditional cash crops include coffee and cocoa, and cotton cultivation increased rapidly since 1990. Small scale-farmers produce most of the food crops such as maize, millet, soybeans, and others. In the villages, the respondent households were selected randomly. The Kabou canton of the Bassar prefecture was selected for the field survey. Adri (1992) stated that about 20 percent of national maize production comes from Kara region (Mokwunye \& Pinto-Toyi, 1991).

This part of Togo is a drought-prone area which receives less than $1000 \mathrm{~mm}$ of rainfall annually, on average. Rain-fed hoe cultivation with limited use of modern inputs for crop production is relied upon by most 
small-scale farmers. The region of the Kara is one of the poorest in Togo and one of the most vulnerable to climatic disasters. The area is about $530 \mathrm{~km}$ north of Lome, the capital of Togo.

\subsection{Data Collection and Sampling Technique}

A panel data survey was conducted in cooperation with the farmers in the Kara region of Togo using a questionnaire. For the purpose to capture the effect of the FISP, we randomly selected two samples of seventy-five farmers each. We used farmer register as a sampling frame to subject the samples; we interviewed the samples about beneficiaries' and non-beneficiaries' questions. In order for the samples to be representative of the portioned population, at least 150 members were selected out of 500 . The respondents were categorized into with FISP and without FISP groups since the program is active and some farmers have been left out due to their personal choice as well as the hardness for arriving their targeting (Vlek, 1990). All data is collected through direct observation. The main idea behind using this method of gathering data is its low cost, simplicity, and originality. However, the study recognizes the downside of the method which may include among others: the difficulty in capturing in-depth data, getting representative samples, lack of accurate responses from respondents (Kessler et al., 2006). Both primary and secondary data were employed. Also, we conducted focus group discussions (FGDs) and a short interview with zones leaders in the study area.

Due to the geographic compactness of the area under study, we assumed similar weather and soil patterns. By holding other factors constant, we also assumed FISP is the only significant difference between the two groups. Therefore, informed by economic theory, logic and compatibility with a priori expectations (Graeub et al., 2016), we focus on the socio-economic characteristics and income to better evaluate the impact of FISP.

\subsection{Theory and Conceptual Framework}

Conceptually, a FISP pack can have either a positive direct or indirect impact on beneficiaries' income (Dorward, 2009). The beneficiary household receives subsidies at a lower price than the market price, resulting in consumer surplus. Furthermore, beneficiaries may choose to open up new areas for maize cultivation which would increase labor demand, or may increase fertilizer dosages in their existing maize fields. Either choice will increase total production, which may result in grain surplus that can be sold to increase household income. In Malawi, fertilizer subsidies were found to lead to small increases in income of all agricultural households (Minde et al., 2008), while in Tanzania improved input use and yields were higher among input subsidy beneficiaries than non-beneficiaries (Minot \& Benson, 2009). In Rwanda, the Agricultural Input Subsidy Program (AISP) accounted for increases in maize production ranging between 158,746 and 424,800 RWF per hectare (Ekise et al., 2013)

Concerning the expected changes in beneficiary $(\mathrm{BHH})$ and non-beneficiary (NBHH) household income during fertilizer subsidy program between a period $(t)$ and $(t+1)$, the authors of the paper use a modified diagrammatic illustration (Ricker-Gilbert et al., 2010), presented in Figure 1. Time $(t)$ represents the growing season in which the household receives subsidized fertilizer. The first question is whether or not there will be a significant contemporaneous boost to household income from fertilizer subsidies by the start of the next growing season $(t+$ $1)$ ? The ex-ante expectation is that a subsidy beneficiary household would have a contemporaneous boost in its income. For example, the subsidy may help increase household fertilizer use due to reduced budget constraints as a result of subsidy. 


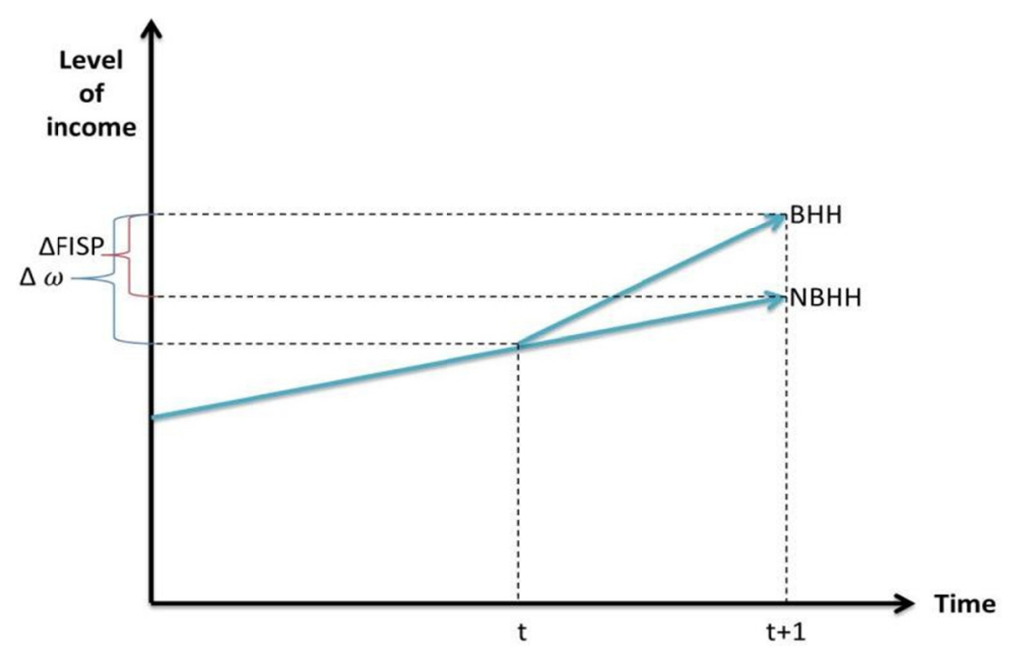

Figure 1. Household Income during Subsidized Fertilizer Period, (time $t$ and $t+1$ )

Note. Income variation $(\Delta \omega)$ from the time $(t)$ between Beneficiary households $(\mathrm{BHH})$ and non-beneficiary households $(\mathrm{NBHH})$ in connection with the amount of FISP ( $\triangle$ FISP) used to the start of the next growing season $(t+1)$. Source: created by the authors according to Ricker-Gilbert et al. (2010).

In this research, the income variation $(\Delta \omega)$ represents the change in income the household experiences between $t$ and $t+1$. However, because $\Delta \omega$ happens over a period of time $(t)$ to $(t+1)$, it would be wrong to attribute its magnitude to FISP alone, as the beneficiary households would still have experienced some change in their income, had not participated in the program. The exact change in household income attributed to FISP alone is $\Delta$ FISP. Numerous factors influence the size of $\Delta$ FISP, such as the size of inputs, the surplus consumption spending pattern, and whether subsidies are used on new land or not. Other factors include household size, labor hired for an increased workload as a result of the received investment, size of grain surplus, the location of the household from grain market areas, and how the revenue from the sale of the surplus grain is used. The factors that affect $\Delta \omega$, with a value of $\Delta \omega$ minus $\Delta$ FISP, would include soil fertility, amount of rain for the season, and management practices used. Based on our reservation, in our study, PSM is used to control these factors and find $\triangle$ FISP alone.

\subsection{Empirical Models}

In determining the impact of FISP, a policy intervention program faces a problem of selection bias because the selection process of beneficiaries is not a random. This usually results in biased and inconsistent estimation due to endogeneity. In order to solve the problem, statistical methods are utilized that simulate an experiment, as cited in studies by Williams (2009) and Giovannetti et al. (2015).

In policy evaluation, there are two possible outcomes based on the outcome when the household participates in the program or does not participate, denoted by $Y_{1}$ and $Y_{0}$ respectively. In the form of an equation, the difference of households' outcomes $\Delta$ is expressed as follows:

$$
\Delta=\mathrm{Y}_{1}-\mathrm{Y}_{0}
$$

However, an essential evaluation problem arises in using Equation (1) because only one potential outcome is observed for each household. Therefore, as Pearl (2015) states, estimating the causal effect of a program involves solving for the counterfactual outcome and requires the use of methods that allow the identification of the relevant impacts in the absence of the data. In the case of FISP, we want to know the change in household income when the household is a beneficiary of the program and when it is not, but the available data only address the former.

Therefore, for any household, the observed outcome (Y), following Lee (2005) and Robinson (2003), is defined as:

$$
\mathrm{Y}=\mathrm{FY}_{1}+(1-\mathrm{D}) \cdot \mathrm{Y}_{0}
$$

Where $\mathrm{F}$ denotes participation in FISP program and takes the values 1 (if the household participates), or 0 otherwise. Written as a function of observable factors likely to impact on FISP (X) and non-observable $\left(U_{1}, U_{0}\right)$, it is specified as follows: 


$$
\begin{aligned}
& \mathrm{Y}_{1}=\mathrm{g}_{1}(\mathrm{X})+\mathrm{U}_{1} \\
& \mathrm{Y}_{0}=\mathrm{g}_{0}(\mathrm{X})+\mathrm{U}_{0}
\end{aligned}
$$

Because FISP beneficiaries and non-beneficiaries have different observable and non-observable characteristics, the two groups will have equally different outcomes. In order to successfully achieve the study objectives, propensity score matching (PSM) technique is adopted. PSM has the benefit of taking into consideration counterfactual, therefore eliminating selection bias and endogeneity in Equation (1). The assumptions of PSM makes it suitable in this study, the conditional independence assumption (CIA) which indicates that potential outcome ( $\mathrm{Y})$ is independent of treatment assignment given a set of observable covariates $\mathrm{X}$ which are not affected by the treatment (Equation 4). Moreover, the other is the 'common support,' means the overlap condition rules out of the phenomenon of perfect predictability of D given $\mathrm{X}$ (Equation 5):

$$
\begin{gathered}
{[\mathrm{Y}(0), \mathrm{Y}(1)] \perp \mathrm{D} \mid \mathrm{X}} \\
0<\mathrm{P}(\mathrm{D}=1 \mid \mathrm{X})<1
\end{gathered}
$$

Therefore, the average effect on the treated (ATT) is estimated (Equation 6), after matching based on the assumptions given above. Each treatment observation $i$ is matched with $j$ control observations regarding their outcome $\left(\mathrm{Y}_{1 \mathrm{i}}\right.$ and $\left.\mathrm{Y}_{0 \mathrm{j}}\right)$.

$$
\mathrm{ATT}=\frac{1}{\mathrm{n}_{1}} \sum_{\mathrm{i} \in(\mathrm{F}=1)}\left[\mathrm{Y}_{1 \mathrm{i}}-\mathrm{Y}_{0 \mathrm{j}}\right]
$$

Where, $\mathrm{F}=1$ = FISP beneficiaries; $\mathrm{D}=0=$ non FISP beneficiaries; $\mathrm{Y}=$ Revenue from maize production.

\subsection{Analysis and Computation Methods}

We used Stata version 14.0 to analyze and estimate the ATT of FISP. First, means and proportions of variables for the whole sample were analyzed, and the characteristics between the beneficiary and non-beneficiary households were compared. Some characteristics were then selected for use as explanatory variables in the estimation of the propensity score (PS) and treatment outcome. The FGD with farmers and existing literature also assisted in the selection of these variables.

The logit model is employed to estimate the PS. The dependent variable, FISP, equaled one for beneficiary household and zero if otherwise. Various specifications of the model were tried until satisfactory, robust results that satisfied the balancing test (PS test) on the covariates used were obtained. Probability distribution graphs were also constructed after matching for visual assessment of the matching (Figure 2).

\section{Results and Discussion}

\subsection{An overview of the FISP and the General Socio-economic Situation of the Respondents}

We begin by reporting an overview of the FISP and the general socio-economic situation in some of the zones in the Kara region (known as Bassar) based on the zone leaders' perceptions obtained during FGDs. An interview conducted by our field workers on farmers on 16 May 2018 revealed that some of them had a positive perception about FISP. The groups argued that the program had generally improved the economic situation of the beneficiaries on two fronts, namely food security and start-up capital. They acknowledged the program was especially useful for those with good agricultural skills. The groups observed that most non-beneficiaries had already run out of food by the time of this interview. They, therefore, concluded that the beneficiaries were better-off from non-beneficiaries.

On the question of why some farmers did not benefit from FISP, the groups disclosed they were generally not interested and that some felt the registration process was too demanding. They ruled out affordability, saying it was very cheap and was done only once for membership. The groups added some farmers lacked the knowledge about cooperatives. However, contrary to their view, data show about $55 \%$ feel they never had the money at the time of registration for membership, while only $26 \%$ expressed personal choice. There could be issues of selfselection where only those who can afford become members. When coupled with the lack of baseline socio-economic indicators, this factor may bias the research findings by underestimating the effect of the FISP. However, there was a general willingness among the farmers to join the FISP in the zones, but it seemed the program had reached its allocation ceiling thereby denying them of an opportunity, they observed. This may raise the issue of "targeting" which could disadvantage some, leading to further biases in the findings of this research. FISP only deals with cooperatives, not individuals. What seems procedural is registration of the new cooperatives with the "registrar of societies" in the Ministry of agriculture. However, members are free to join existing cooperatives at a minimal fee instead of forming new ones, though they still have to pay the $50 \%$ input cost share. 
The group members mentioned the lack of competitive urge among the farmers as far as maize production was concerned. They implored the government to diversify the program into livestock, fish farming and irrigation (Kassam, 2009). They stressed possession of draft animals was very important for the farmers because they were a great utility, despite associated disease and rustling problems. Also, draft animals may have a "social status" against associated welfare, i.e., more wealthy.

\subsection{Descriptive Statistics}

The descriptive statistics display the household characteristics used in matching and the outcome variable on which the average treatment effect on the treated (ATT) was estimated (Table 1). Although some beneficiaries share the pack and some households have multiple beneficiaries (Bott et al., 2009), in our sample all beneficiaries receive a single pack ( $10 \mathrm{~kg}$ of maize seed and $200 \mathrm{~kg}$ of chemical fertilizers), and all households have sole beneficiaries.

Table 1 shows that employing the conventional t-test approaches, in analyzing the differences in the household characteristics and various outcome variables, beneficiaries were better-off than the non-beneficiaries.

On average, beneficiary farmers have larger families and more cultivated land. The average family size for beneficiary farmers is eight persons per household, while the family size for non-beneficiary farmers is only six members per household. Approximately half of the family members in either group are above the age of 40 , so they can all contribute to the labor force. Beneficiaries have an average of 6.2 hectares of cultivated land per household, of which 3.6 hectares were used for maize production crop, while non-beneficiaries only had 0.3 hectares of their 0.9 hectares under maize cultivation in the last farming season. Rashid et al. (2004) found that farmers with relatively large land areas are more likely to participate in FISP.

The majority of the households in the sample are led by males with $69.3 \%$ and $54.6 \%$ respectively of non-beneficiary and beneficiary households being male-led. The fact that both of the groups are over $50 \%$ male-led shows that gender has no significant effect of benefiting from FISP, contrary to our expectations (Table $1)$.

The differences in the level of education of the household head among beneficiaries and non-beneficiaries were not statistically significant. On averages, beneficiaries have been farming for 25 years and non-beneficiaries for 19 years, which suggests that beneficiary household heads are more experienced in cultivating maize than non-beneficiaries.

On average, non-beneficiary households have relatively weaker economic conditions. In our sample, apart from having less cultivated land, the average income for the past two crop seasons (2016/17-2017/18) for non-beneficiary households is twice less than that of the beneficiary households. Non-beneficiaries have less per capita income (4,904.46 CFA) than beneficiaries (80,492.21 CFA) in the 2017/18 crop season. Moreover, non-beneficiary households have lower annual expenditures $(30,608.35 \mathrm{CFA})$ than beneficiary households (287,356.86 CFA). 
Table 1. Definition of variables and descriptive statistics

\begin{tabular}{lllll}
\hline \multirow{2}{*}{ Variable name } & Description of variable & Whole sample & Non-beneficiaries & Beneficiaries \\
\cline { 3 - 5 } & & $(\mathrm{N}=150)$ & $(\mathrm{N}=75)$ & $(\mathrm{N}=75)$ \\
\hline Explanatory variables & & & & \\
Family Size & Average number of people in a household & $8.587(26.65)$ & $6.524(0.224)$ & $8.6533(0.674)^{*}$ \\
Age & The average Age of the HH & 52.87 & 49.48 & 56.2669 \\
Farm Size & Land possessed by farm household in hectares & $3.587(14.47)$ & $0.966(0.882)$ & $6.206(1.965)^{* *}$ \\
Maize Farm Size & Land used for maize cultivation in hectares & $0.967(14.39)$ & $0.333(0.502)$ & $3.6(0.545)^{* * *}$ \\
Gender & Percentage of male HH & $62.0(15.59)$ & $69.3(0.464)$ & $54.6(0.501)$ \\
Education & Education of HH & 4.753 & 4.8932 & 4.6133 \\
Farming Experience & Number of HH's years of farming & $22.79(25.96)$ & $19.706(9.072)$ & $25.866(11.449)$ \\
Marital status & Percentage of married HH & $1.313(21.91)$ & $1.32(0.719)$ & $1.306(0.752)$ \\
Distance & Distance to the nearest town in Km & $23.66(0.84)$ & $25.15(1.36)$ & $22.56(1.05)$ \\
Outcome variables & & & & \\
Av Income (FRA) & Average 2 years income in CFA from FRA & $253,264.73(18,059)$ & $187,645.66(22,787)$ & $301,361.01(25,926.05)^{* * *}$ \\
Av Income (HH market) & Average 2 years income in CFA from & $11,187,546(11,478)$ & $903,236.93(2,708.9)$ & $21,493,649(6,586,607)^{* * *}$ \\
& maize market & & & \\
Av Income (Current) & Average Income during 2017/18, CFA & $165,668.18(13,942)$ & $112,316.18(15,426)$ & $204,772.77(20,903.28)^{* * *}$ \\
Per capita Income & Per capita income during 2017/18, CFA & $42,698.31(41,815.9)$ & $4,904.46(9,738.25)$ & $80,492.21(23,034.29)^{* * *}$ \\
Expenditure & HH expenditure during 2017/18, CFA & $158,982.63(149.61)$ & $30,608.35(31,819.71)$ & $287,356.86(103,224.87)^{* * *}$ \\
\hline Note. Figures in
\end{tabular}

Note. Figures in parentheses are standard errors of the mean. ${ }^{*}, * *, * *$ indicates statistical significance levels at $10 \%, 5 \%$, and $1 \%$, respectively.

\subsection{Determination of the Effect of FISP on Beneficiaries}

Before estimation of the average treatment effect on the treated (ATT), a logistic model was employed to determine factors that affect FISP participation. Table 2 reveals that maize cultivated area, farming experience, and farm size significantly influence the likelihood of being a beneficiary. Our results are consistent with the theory with the additional maize land cultivation and farming experience, the chance of being on FISP is high. Contrary to our expectations, marital status, education, gender, family size, and age do not affect the probability of being on FISP. Regarding the quality of our model specifications, the value of log likelihood and significant chi-square (36.800) indicates that the model used is appropriate for estimation, and this is validated by the use of all the observational data in the study.

Table 2. Log Likelihood of logistic regression

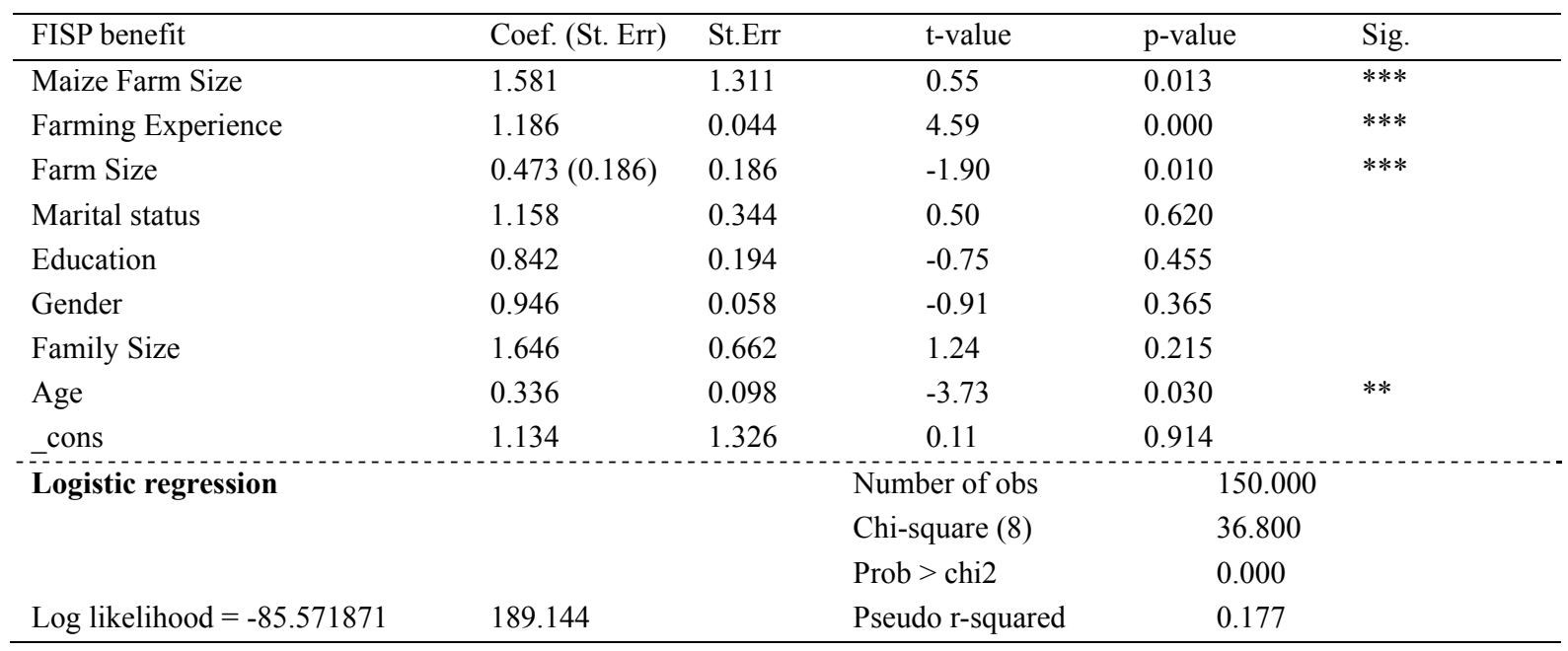

Note. $* * * \mathrm{p}<1 \%, * * \mathrm{p}<5 \%,{ }^{*} \mathrm{p}<10 \%$.

The numbers with stars are standard errors of the mean $*, * *, * * *$ indicates statistical significance levels at $10 \%$, $5 \%$, and $1 \%$, respectively. 
To ensure that the estimates of ATT are reliable and consistent, Table 3 and Figure 2 give an account of the quality of matching. As it was already established in the methodology, for a match to be acceptable, the 'common support' and covariate balance needs to lead to a reduction in mean bias between the beneficiary and non-beneficiary. This end, Figure 2 displays the distribution of the 'common support' confirming equality of comparable characteristics between the groups, while Table 3 displays the differences in the comparable characteristic between the two groups are insignificant (refer to that column under $\mathbf{p}>\mathbf{t}$ ). Moreover, the lower part of Table 3 gives evidence of bias reduction on account of matching, because a covariate balance test (PS-test) assesses the quality of matching and, by extension, the validity of the causal inference. We, therefore, drop any observation that lies outside the range of propensity scores, or that overlap across treatment, and comparison groups through the use of "common" in the syntax.

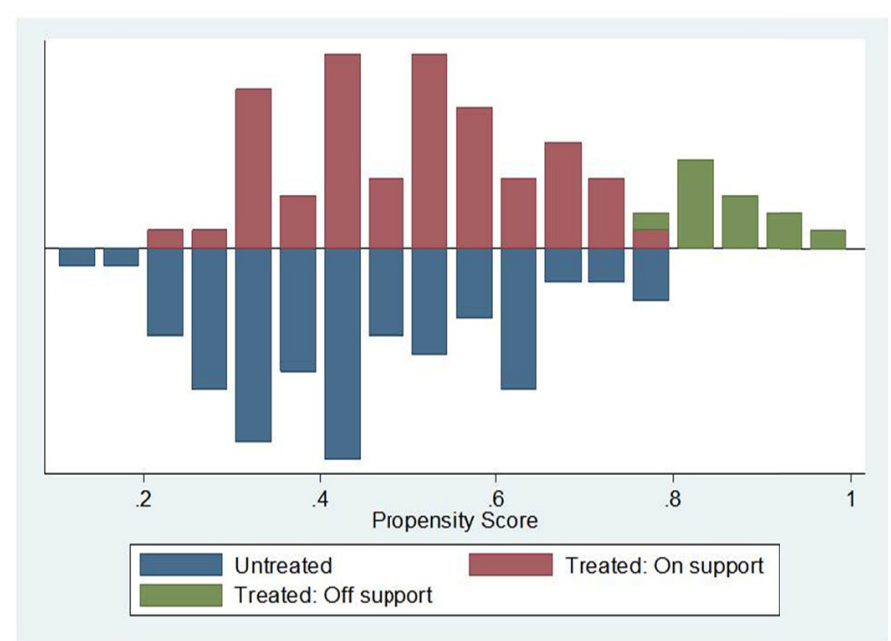

Figure 2. Propensity score distribution and 'common support' for propensity score estimation

Notes. Treated: on support" indicates the observations in the adoption group that have a proper comparison (untreated). "Treated: off support" indicates the observations in the adoption group that do not have a suitable comparison.

Table 3. Covariate balance test (pstest) results

\begin{tabular}{|c|c|c|c|c|c|c|}
\hline \multirow{2}{*}{ Variable } & \multirow{2}{*}{ Treated } & \multirow{2}{*}{ Mean Control } & \multirow{2}{*}{ \%bias } & \multicolumn{2}{|c|}{ t-test } & \multirow{2}{*}{$\mathbf{V}(\mathbf{T}) / \mathrm{V}(\mathrm{C})$} \\
\hline & & & & $\mathbf{t}$ & $p>t$ & \\
\hline Maize Farm Size & 8.4603 & 8.2827 & 4.5 & 0.27 & 0.788 & 0.88 \\
\hline Farming Experience & 22.46 & 22.158 & 2.9 & 0.19 & 0.849 & 1.01 \\
\hline Farm Size & 1.0635 & 1.0509 & 5.3 & 0.30 & 0.763 & 1.23 \\
\hline Marital status & 1.3333 & 1.2651 & 9.3 & 0.53 & 0.595 & $1.67 *$ \\
\hline Education & 1.127 & 1.1459 & -2.3 & -0.12 & 0.901 & $1.75^{*}$ \\
\hline Gender & 0.61905 & 0.5905 & 5.9 & 0.32 & 0.746 & \\
\hline Family Size & 2.3492 & 2.3853 & -4.6 & -0.27 & 0.789 & 1.06 \\
\hline Age & 0.946 & 0.058 & -0.91 & 0.365 & 0.946 & 0.058 \\
\hline \multicolumn{7}{|c|}{ * if variance ratio outside $[0.61 ; 1.65]$} \\
\hline LR chi2 & $\mathrm{p}>$ chi2 & Mean Bias & Med Bias & $\mathrm{B}$ & $\mathrm{R}$ & $\% \operatorname{Var}$ \\
\hline 0.005 & 0.997 & 5.0 & 4.6 & 16.3 & 0.96 & 33 \\
\hline
\end{tabular}

Note. ${ }^{*}$ if B $>25 \%, \mathrm{R}$ outside $[0.5 ; 2]$.

Based on our analysis before matching, the mean differences in the outcome variables between the two groups were significantly higher than expected by FISP, as the cause cannot be dismissed. Evaluating the impact of FISP on beneficiary household income using more meticulous econometric analytical tools confirmed the positive effect of FISP on beneficiary income from cultivation of maize and per capita income (Table 4). Estimates from both matching approaches (kernel and nearest neighbor), though slightly different, indicate that FISP has a robust, 
positive and significant effect on maize income. Therefore, the mean differences in beneficiary and non-beneficiary household income may be attributed to household participation in the program, more than household characteristics. The two matching algorithms, Nearest Neighbor (2) (NN (2)) and Kernel (kernel type normal), are widely used by researchers in order to check for robustness in the estimates. If both methods estimate statistically significant provide that are close in value, it can be concluded that FISP tends to have an effect on beneficiary households, and if it is only under one method that the estimate is statistically significant, but both estimates have similar values, the same conclusion would be sound but less robust. Although we did not experience the third possible outcome, estimates from the two matching methods are statistically significant although different display values.

Table 4. The average treatment effect on the treated (ATT) of FISP on beneficiary households outcome variables

\begin{tabular}{lllllll}
\hline \multirow{2}{*}{ Outcome variables } & \multicolumn{2}{c}{ ATT-NN (2) } & & \multicolumn{2}{c}{ ATT-Kernel (normal) } \\
\cline { 2 - 3 } \cline { 6 - 7 } & Units & \% & & Units & \% \\
\hline Av. Income HH 2years,CFA & $57,476.86(34,003.84)^{* *}$ & 40.23 & & $47,168.34(27,993.08)^{* *}$ & 30.79 \\
Av. Income during 2017/18,CFA & $65,668.18(13,942.3)$ & 37.46 & & $56,113.51(19,443.57)^{* * *}$ & 34.42 \\
Av. Income FRA 2years,CFA & $84,441.76(47,455.54)^{* *}$ & 40.06 & & $50,606.94(37,336.86)^{*}$ & 20.69 \\
Av. Fertilizer usage 2years, kg/ha & $74.09(17.95)^{* * *}$ & 28.85 & & $81.85(14.59)^{* * *}$ & 32.87 \\
Per capita Income 2017/18,CFA & $13,786.83(5,785.56)^{* * *}$ & 47.52 & & $14,144.74(5,106.07)^{* * *}$ & 47.52 \\
Total HH expenditure 2017, CFA & $38,802.38(21,677.2)^{* *}$ & 27.46 & & $46,113.51(19,443.57)^{* * *}$ & 34.42 \\
\hline
\end{tabular}

Note. Figures in parentheses are standard errors of the average treatment effect on the treated (ATT) *, **, *** indicates statistical significance levels at $10 \%, 5 \%$, and $1 \%$, respectively.

\subsection{ATT on Beneficiary Household Actual Maize Income}

Estimates for the effect of FISP on beneficiary household incomes are estimated in two ways: i) using farmer's considered (actual) incomes and, ii) the estimated revenue from maize production based on FRA set price.

For the first case, based on actual farmer incomes, we estimate (kernel approach) an average increment in household annual income from maize sales of $30.8 \%$ for 2016/17 and 2017/18 crop seasons, and total household income by $13.9 \%$. Per capita annual income from maize in 2016/17 season is estimated to have increased by $14,144.74 \mathrm{CFA}$, which translates to $38.745 \mathrm{CFA}$ per capita/day income and is equivalent to 0.07749 USD (exchange rate of $1 \mathrm{USD}=500 \mathrm{CFA}$ ). An income increase of $0.07749 \mathrm{USD}$ per capita/day means a reduction of $6.4 \%$ in property (relative to $2 \mathrm{USD} /$ Day poverty line), and $10.24 \%$ relative to extreme poverty ( $1.25 \mathrm{USD} / \mathrm{Day}$ poverty line). Our estimates of FISP's impact on farmer household poverty severity are higher than Charles and Hwang (2011), who find that $200 \mathrm{~kg}$ of subsidized fertilizer reduces poverty severity by $2.7 \%$ and extreme poverty severity by $3.6 \%$. This may be attributable to the failure of Charles and Hwang (2011) to include the seed component in their analysis and, as such, underestimate the impact of FISP. Although our estimates are higher, the per capita increment resulting from FISP is still not large enough to lift households above the poverty line.

For the second case, estimates of the average increment during the two years in beneficiary household total revenue from maize production using the prices set by FRA are less robust than expected. In comparison to the estimates from farmer income, maize revenue increases by $18.9 \%$ when selling to FRA. Although selling to FRA is profitable, farmers in the FDGs stated that the late opening of the maize market and late payments prevent them from selling to FRA.

\subsection{ATT on Fertilizer Usage}

Increasing fertilizer usage among small-scale farmers is one of the means through which FISP intends to meet its objectives. At a $50 \%$ level of subsidy, ceteris paribus, a FISP pack should increase household fertilizer usage by $200 \mathrm{~kg}$ (a full pack is $200 \mathrm{~kg}$ ); however, the per unit increment is low. We estimate an increase in beneficiary household maize fertilizer usage of $81.9 \mathrm{~kg} / \mathrm{ha}$ (kernel) for the two years (2016/17 and 2017/18 crop seasons), which accounts for a $32.9 \%$ increase. Estimates of average fertilizer usage for 2016/17 and 2017/18 crop seasons also show similar increments.

\subsection{ATT on Beneficiary Household Expenditure}

We also estimated the average increment in household expenditure due to FISP and found that increases beneficiary household expenditure by $34.4 \%$ (CFA 46,100.32) (kernel). This change in expenditure is higher than 
our estimated increase in income from FISP (Table 5). In other words, on average the effect of FISP on household income is not transferred to the subsequent crop season. This substantiates the complaints by many farmers during the FGDs, that FISP cannot improve their capital base because its effect helps them only to solve some consumption problems.

Table 5. Average treatment effect (ATE) of FISP on income

\begin{tabular}{llllll}
\hline \multirow{2}{*}{ Outcome variables } & \multicolumn{2}{c}{ ATE-NN (2) } & & \multicolumn{2}{c}{ ATE-Kernel (Normal) } \\
\cline { 2 - 3 } \cline { 5 - 6 } & Units & $\mathbf{\%}$ & & Units & \% \\
\hline Av Income 2years, CFA & $41,162.04 * *$ & 30 & & $43,874.55^{* *}$ & 31.21 \\
\hline
\end{tabular}

Note. $* * *, * * *$ indicates statistical significance levels at $10 \%, 5 \%$ and $1 \%$ respectively.

\section{Conclusions}

Since the introduction of the Farmer Input Support Program (FISP) in Togo, several studies evaluating its performance have been conducted. However, while the methodologies used in these studies for evaluating the effect of FISP on household income shows a relationship between FISP and income, they do not take into consideration the seed component of the program and a perfect resulted in an underestimation of the program effect on income. To address this, we use Propensity Score Matching (PSM) to measure the effect of a FISP pack (including both fertilizer and seed) on household income using data collected from Kara region of Togo between February and May 2018.

Our results show that FISP increases actual household maize income by $30.8 \%$. Based on the price set by the Food Reserve Agency (FRA), household maize income would increase by $40 \%$. FISP also increases fertilizer usage by $81.9 \mathrm{~kg} / \mathrm{ha}$. Households maize production was found to have increased by 1 ton in the $2016 / 17 \mathrm{crop}$ season. Furthermore, FISP was found to increase household expenditure among beneficiaries by $34.4 \%$ (46,100.32 CFA).

However, despite the large percentage of the estimated effect of FISP on household income, the per capita increment is tiny. An increase of 30.8\% in household income translates to 38.732 CFA (0.07749 USD) per capita/day income. This increment reduces relative poverty ( 2 USD/Day poverty line) by $6.4 \%$ and $10.24 \%$ relative to extreme poverty (1.25 USD/Day poverty line). Therefore, these are not large enough investment to lift households above the poverty line. This can be attributed to the low maize production among beneficiaries caused by, among other factors, low rates of fertilizer use despite FISP being a full package of seeds plus fertilizer. In order to improve FISP's ability to reduce poverty, consideration should be given to measures that offer more technical support to farmers to ensure more efficient use of fertilizer.

While we addressed the limitations of previous studies by taking into consideration the seed and fertilizer component, our sample is from one region and is not nationally representative. As such, our findings are limited to northern regions. It would be instructive for future studies to estimate the impact of the "FISP pack" using a nationally representative sample.

\section{Acknowledgements}

This research was funded by the National Natural Science Foundation of China [71573127] and the Natural Science Foundation of Jiangsu Province of China [BK20171384]. We are thankful for technical support and assistance of Prof. Li Xiangmei (Prof. College of Economics and Management), China Center for Food Security Studies, College of Economics and Management, Nanjing Agricultural University, Nanjing 210095, Jiangsu, China.

\section{References}

Abalo, K. (2009). Poverty and the Anthropometric Status of Children: A Comparative Analysis of Rural and Urban Households in Togo.

Adri, K. (1992). The potential for growing rainfed maize in Togo. Paper presented at the Influence du Climat sur la Production des Cultures. Ouagadougou, Burkina Faso.

Alfred, M., Bhaskarreddy, G., \& Singh, B. R. (1993). Fate of Fertilizer-15N to a Maize Crop Grown in Northern Zambia. Acta Agriculturae Scandinavica, 43(4), 231-237. 
Ametoglo, M. E. S., \& Guo, P. (2016). Inequality, poverty and inclusive growth in TOGO: An Assessment of the Survey Data. MPRA Paper.

Antwi, A., \& Cissé, A. H. (n.d.). How can social protection contribute to food security and nutrition in West Africa?

Atake, E. H., \& Amendah, D. D. (2018). Porous safety net: Catastrophic health expenditure and its determinants among insured households in Togo. Bmc Health Services Research, 18(1), 175. https://doi.org/10.1186/ s12913-018-2974-4

Binswanger, H. (1989). The policy response to agriculture. The World Bank Economic Review, 3(Suppl. 1), 231-258. https://doi.org/10.1093/wber/3.suppl_1.231

Bott, D. M., Kapp, M. C., Johnson, L. B., \& Magno, L. M. (2009). Disease management for chronically ill beneficiaries in traditional Medicare. Health Affairs, 28(1), 86-98. https://doi.org/10.1377/hlthaff.28.1.86

Cafer, A. (2014). Sustainable Intensification and the 2013 Montpellier Panel.

Charles, M., \& Hwang, H. C. (2011). Subsidized Fertilizer Distribution Method in Zimbabwe. Journal of Korean Society of Rural Planning, 17(4), 39-50. https://doi.org/10.7851/ksrp.2011.17.4.039

Chirwa, T. G. (2010). Program evaluation of agricultural input subsidies in Malawi using treatment effects: Methods and practicability based on propensity scores.

Crawford, E. W., Jayne, T. S., \& Kelly, V. A. (2006). Alternative approaches for promoting fertilizer use in Africa. Agriculture \& Rural Development Department, World Bank Washington, DC.

Czyzewski, A., \& Stepień, S. (2017). New economic foundations of the common agricultural policy (CAP) of European Union. Ekonomista, 2017(6), 675-697.

Dorward, A. (2009). Rethinking Agricultural Input Subsidy Programmes in Developing Countries.

Ekise, E., Nahayo, A., Mirukiro, J., \& Nsengiyumva, B. (2013). Analysis of the impact of agricultural input subsidies voucher programme on the livelihoods of small-scale maize producers in Kirehe District, Eastern Rwanda. NY Sci J, 6(9), 32-44.

El-Fouly, M. M., \& Fawzi, A. F. A. (1995). Higher and better yields with less environmental pollution in Egypt through balanced fertilizer use. Fertilizer research, 43(1-3), 1-4.

Funsani, W., Rickaille, M., Zhu, J., Tian, X., Chibomba, V., Avea, A. D., \& Balezentis, T. (2016). Farmer Input Support Programme And Household Income: Lessons From Zambia's Southern Province. Transformations in Business \& Economics, 15.

Giovannetti, G., Marvasi, E., \& Sanfilippo, M. (2015). Supply chains and the internationalization of small firms. Small Business Economics, 44(4), 845-865.

Graeub, B. E., Chappell, M. J., Wittman, H., Ledermann, S., Kerr, R. B., \& Gemmill-Herren, B. (2016). The state of family farms in the world. World Development, 87, 1-15.

Green, R. H. (1986). Hunger, poverty and food aid in Sub-Saharan Africa: Retrospect and potential. Disasters, 10(4), 288-302.

Jones, P. G., \& Thornton, P. K. (2003). The potential impacts of climate change on maize production in Africa and Latin America in 2055. Global Environmental Change, 13(1), 51-59.

Kassam, A. (2009). Agriculture at a Crossroads: Synthesis Report of the International Assessment of Agricultural Knowledge, Science, and Technology for Development (IAASTD). In B. D. McIntyre, H. R. Herren, J. Wakhungu, \& R. T. Watson (Eds.), Experimental Agriculture (Vol. 46, No. 1, pp. 115-116). Washington, DC. https://doi.org/10.1017/S0014479709990676

Kazis, P. (2012). Agricultural Subsidies in the U.S.: Where Political Rent-Seeking Trumps Economic Reality.

Kenny, A. L. (2007). Optimal Land Allocation of Maize, Cassava and Teak for Small Landholders in Southern Togo, West.

Kessler, R. C., Akiskal, H. S., Ames, M., Birnbaum, H., Greenberg, P., Hirschfeld, R. M., .. Wang, P. S. (2006). Prevalence and effects of mood disorders on work performance in a nationally representative sample of U.S. workers. Am J Psychiatry, 163(9), 1561-1568.

Lee, M. J. (2005). Micro-econometrics for policy, program, and treatment effects. Oxford University Press.

Li, C. (2014). U.S. New Mechanisms of Agricultural Subsidies and Its Future Prospect. Agricultural Outlook. 
Makunka, C. (2012). The performance of the FAO voucher scheme as a method of input procurement and distribution in Zambia: A case study of Chongwe and Mazabuka//cCynthia Makunka. Humanities and Social Sciences (p. 749).

Minde, I. J., Jayne, T. S., Crawford, E., Ariga, J., \& Govereh, J. (2008). Promoting fertilizer use in Africa: current issues and empirical evidence from Malawi, Zambia, and Kenya. Citeseer.

Minot, N., \& Benson, T. (2009). Fertilizer subsidies in Africa. IFPRI-Issue Brief. Washington DC.

Mokwunye, A. U., \& Pinto-Toyi, A. K. (1991). Efficient fertilizer use for increased crop production: The IFDC-Africa experience in Togo. Alleviating Soil Fertility Constraints to Increased Crop Production in West Africa, 47(2), 235-244. https://doi.org/10.1007/978-94-011-3224-4_21

Mougeot, L. J. (2005). Agropolis: The social, political, and environmental dimensions of urban agriculture: IDRC.

Musembi, D. K. (2011). The Dilemma of Using Fertilizer to Power the Green Revolution in Sub-Saharan Africa. Springer Netherlands.

Oya, C. (2009). The World Development Report 2008: Inconsistencies, silences, and the myth of 'win-win'scenarios. The Journal of Peasant Studies, 36(3), 593-601.

Pearl, J. (2015). Generalizing Experimental Findings. Journal of Causal Inference, 3(2), 218-226.

Pretty, J. (1999). Can sustainable agriculture feed Africa? New evidence on progress, processes, and impacts. Environment, development and sustainability, 1(3-4), 253-274.

Rashid, S., Sharma, M., \& Zeller, M. (2004). Micro-Lending for small farmers in Bangladesh: Does it affect farm households' land allocation decision? The Journal of Developing Areas, 13-29.

Rickergilbert, J., Lunduka, R., Shively, G., \& Jayne, T. (2014). Improving the Effectiveness of Malawi's FISP. Food Security Collaborative Policy Briefs.

Robinson, P. M. (2003). Time series with long memory. Our Catalogue, x, 382.

Rosenzweig, M. R., \& Wolpin, K. I. (1993). Credit market constraints, consumption smoothing, and the accumulation of durable production assets in low-income countries: Investments in bullocks in India. Journal of Political Economy, 101(2), 223-244.

Shimizu, K., Masumoto, T., \& Pham, T. H. (2006). Factors impacting yields in rain-fed paddies of the lower Mekong River Basin. Proceedings of Hydraulic Engineering, 4(3), 145-151.

Tittonell, P., \& Giller, K. E. (2013). When yield gaps are poverty traps: The paradigm of ecological intensification in African smallholder agriculture. Field Crops Research, 143, 76-90.

UNICEF. (2000). Poverty reduction begins with children.

Vlek, P. L. (1990). The role of fertilizers in sustaining agriculture in sub-Saharan Africa. Fertilizer Research, 26(1-3), 327-339.

Wendland, K. J., \& Sills, E. O. (2008). Dissemination of food crops with nutritional benefits: Adoption and disadoption of soybeans in Togo and Benin. Paper presented at the Natural Resources Forum.

Williams, L. A. (2009). Statistical methods in marketing management. Electronics \& Power, 14(8), 319-322.

Wodon, Q., Tsimpo, C., Backiny-Yetna, P., Joseph, G., Adoho, F., \& Coulombe, H. (2008). Potential impact of higher food prices on poverty: Summary estimates for a dozen west and central African countries. The World Bank.

\section{Copyrights}

Copyright for this article is retained by the author(s), with first publication rights granted to the journal.

This is an open-access article distributed under the terms and conditions of the Creative Commons Attribution license (http://creativecommons.org/licenses/by/4.0/). 